\title{
Nanoparticles Surface Engineering of Ultradispersed Polytetrafluoroethylene ${ }^{\dagger}$
}

\author{
S.P. Gubin'1, I.P. Dotsenko, G.Yu. Yurkov, \\ D.A. Baranov and N.A. Kataeva \\ N.S. Kurnakov Institute of General and Inorganic \\ Chemistry, Russian Academy of Sciences*
}

\section{A.K. Tsvetnikov}

Institute of Chemistry, Far East Division, Russian Academy of Sciences, pr. Stoletiya **

V.M. Bouznik

B oreskov Institute of Catalysis, Siberian Division, Russian Academy of Sciences, pr. Akademika*t*k

\begin{abstract}
In this work we demonstrate that it is possible to create new optical and magnetic materials based on metal-containing nanopar ticles stabilized on the sur face of polytetrafluor oethylene (PTFE) nanogranules. The magnetic and optical properties of these materials have been investigated. The materials were prepared by a method of thermal decomposition of metal compounds in the heated polytetrafluoroethylene-oil system. Transmission electron microscopy data show that the diameter of the particles is 3-6 nm. Magnetic studies show that for the obtained nanoparticles, the blocking temperature and the magnetic ani sotropy is highest for homometallic nanoparticles; this fact makes it promising material for the different magnetic applications. The optical properties of nanomaterials CdS/ nanogranules of PTFE are specified. The size and core-shell structure of the nanomaterials has been confirmed by TEM and X-ray diffraction.
\end{abstract}

Key words: N anostructures, Nanomaterials, Polymer-matrix composites, M agnetic and optical properties.

\section{Introduction}

Nanoparticles are good building blocks for the fabrication of nanomaterials that vary in composition, structure and properties. From this point of view they are universal, ideally suitable for the design of functional nanomaterials and different sensory and electroluminescent devices, magnetic and fluorescent

Accepted: J uly 26, 2005

* Leninsky av. 31, M oscow, 119991 Russia.

** Vladivostoka 159, Vladivostok, 690022 Russia.

E-mail: tsvetnikov@ich.dvo.ru

***L avrent'eva 5, N ovosibirsk, 630090 Russia.

E-mail: bouznik@ngs.ru

1 Corresponding author

TEL: +7 (095) 954-71-36 FAX: +7 (095) 954-12-79

E-mail: gubin@igic.ras.ru labels, in bioresearches ${ }^{1,2)}$, electronics, as diodes $^{31}$ and lasers ${ }^{4,5)}$, in catalyses ${ }^{6}$, etc.

$M$ aterials that contain different types of nanoparticles have attracted the special attention of investigators in recent years. The unique properties of nanoparticles are determined first of all by the fact that many atoms in a nanoparticle belong to its surface $^{7)}$. Thus, the properties of nanoparticles differ greatly from the corresponding bulk materials.

The creation of the nanomaterials from the nanoparticles is the most perspective for a number of reasons. First of all, it is connected with an infinite variety of the sizes, forms, composition and structure of nanoparticles, obtained by "chemical" methods. It allows the preliminary definition and variation of the physical properties of nanoparticles before using them as "building blocks" for the creation of nanoma- 
evinfortunately, there is only a limited number of W methods leading to the creation of materials from nanoparticles. Agglomeration of the nanoparticles, as a rule, leads to loss of the majority of unique characteristics. M ore often than not, the nanoparticles are entered into matrixes of various types. Thus it is observed that the surface atoms can interact with the matrix where they are embedded. From this point of view, a matrix should have an essential influence on the properties of nanoparticles ${ }^{8)}$. The investigation of the properties of such materials is of both fundamental and practical interest. Polymer matrixes containing nanoparticles constitute an important class of nanostructured materials $\mathrm{s}^{9}$. These materials are especially important for practical applications, since the polymer technology allows the fabrication of samples with various forms and mechanical properties ${ }^{10)}$.

There is another way to engineer nanomaterials; during the recent past, the tendency to fix small (2$10 \mathrm{~nm})$ nanoparticles on the surface of microobjects of spherical form - nanospheres (0.2-20.0 microns) - was outlined. Fig. 1 presents the schematic of that composite microgranule-nanoparticle material. Such combined micro-nano objects possess a number of advantages. Nanoparticles, being localized on a surface, lose the ability to agglomerate remain at the same time accessible for the interaction with external reagents and keep the basic complex of physical char-

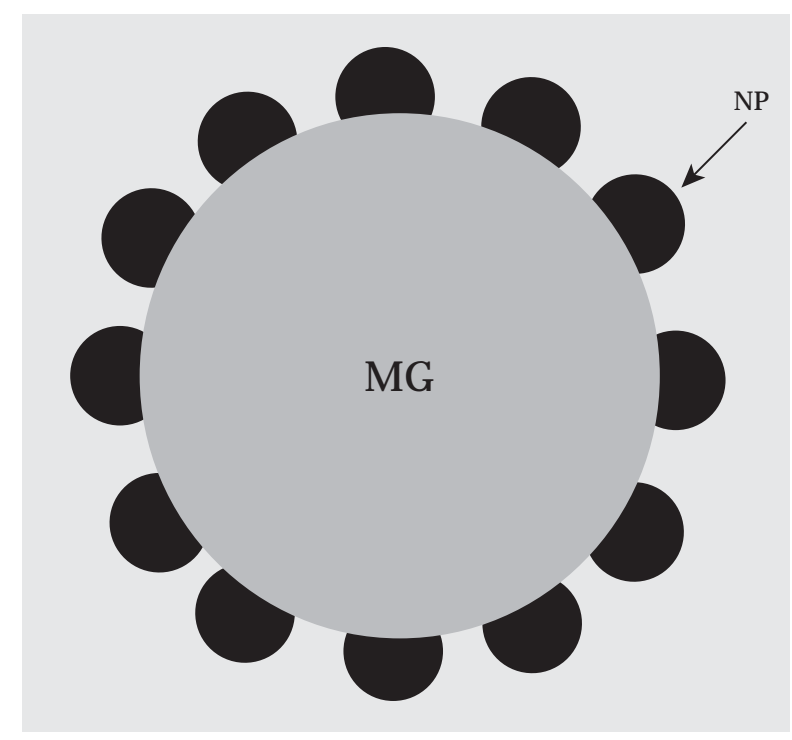

Fig. 1 Schematic of the "polymer core/ nanoparticles shell" composite nanomaterials. acteristics. At the same time it is possible to create "homogeneous" dispersions - sols and aerosols, and to form materials - films, coverings, three-dimensional samples, from such microgranules with the nanoparticles on its surface. The methods of construction of structures from microgranules are better developed. They are easier to manipulate than small nanoparticles that promote the creation of nanomaterials where the arrangement of nanoparticles will be highly organized. Also, the interest in such particles is connected by the fact that the covering of microgranules by the nanoparticles can essentially change their physical and chemical properties; it can lead to new practical applications in electronics ${ }^{11)}$, the creation of displays $^{12)}$, the decision of power problems ${ }^{13,14)}$ and others task ${ }^{15-17)}$.

Most works concentrate on nanoparticulate core/ polymer shell systems with $\mathrm{SiO}_{2}, \mathrm{Au}$ and other cores $^{18,19)}$. There are less works on polymer core/ nanoparticle shell systems, clearly because most polymers are difficult to prepare in the form of nanodispersions ${ }^{20)}$. Therefore, the development of new techniques for stabilizing metallic nanoparticles on the surface of polymer cores is a challenging branch of nanotechnology 21 ). One of the most perspective carriers in this direction is polytetrafluoroethylene.

The polytetrafluoroethylene possesses a set of properties, many of which are unique ${ }^{22)}$.

At the present time, the thermogas dynamic method is available which allows the industrial production of nanogranules of polytetrafluoroethylene with sizes that do not exceed 500 nanometers ${ }^{23-27)}$. The pictures of nanogranules of polytetrafluoroethylene obtained by this method are shown in Fig. 2. The microphotographs were obtained using transmission electronic microscopy (TEM), atomic-force microscopy (AFM) and scanning electronic (SEM) microscopy.

In our research work, polytetrafluoroethylene (PTFE) nanogranules of $100-500 \mathrm{~nm}$ in diameter are used to immobilize the nanoparticles. On the surface of such granules, we can stabilize nanoparticles of magnetic materials, nanoparticles of selenides and sulfides of metals (so-called quantum dots) and nanoparticles of rare-earth and noble metals.

In this article, the synthesis of magnetic ( $\mathrm{Fe}, \mathrm{Co}$ ) and semiconducting (CdS) nanoparticles localized on the granules of polytetrafluoroethylene and their unique physical properties will be considered. 

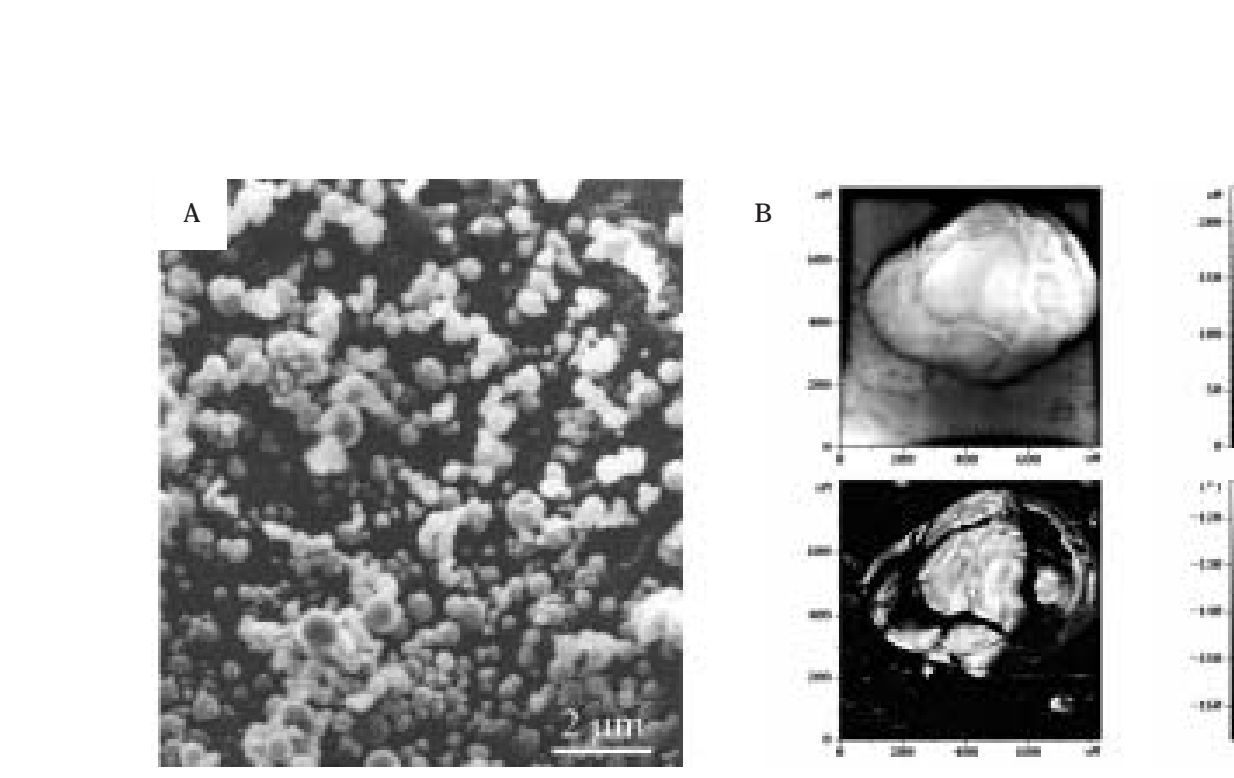

C

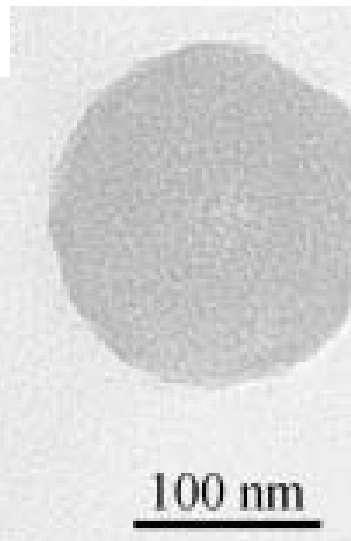

Fig. 2 M icrophotographs of polytetrafluoroethylene nanogranules. ( $A, B, C,-S E M, A F M, T E M$ images, respectively).

\section{Experiment}

Early on, a universal method which allows the fabrication of large amounts of nanocomposites with metal-containing nanoparticles stabilized in polymer matrixes was developed ${ }^{28-30)}$. The encapsulation was done by the thermal decomposition of metal-containing compounds ( $\mathrm{MRn}$; $\mathrm{M}=\mathrm{Cr}, \mathrm{M} \mathrm{O}, \mathrm{W}, \mathrm{Ti}, \mathrm{Zr}, \mathrm{Fe}, \mathrm{Co}$, $\mathrm{Ni}, \mathrm{Pd}, \mathrm{Pt}$, Cu etc; $\mathrm{R}=\mathrm{CO}, \mathrm{HCOO}, \mathrm{CH}_{3} \mathrm{COO}, \mathrm{C}_{2} \mathrm{O}_{4}$, $\mathrm{C}_{6} \mathrm{H}_{5} \mathrm{CH}_{2}$ ) in solution/ melt of polymer (polyethylene, polypropylene, polyamide, polyacrylate, polycarbonate, polystyrene, polyesters, polyphenyleneoxide, siloxane) ${ }^{29,30)}$. In this work, this method was used to immobilize nanoparticles on the surface of ultradispersed polytetrafluoroethylene (PTFE) nanogranules.

$M$ etal-containing nanoparticles on the surface of UPTFE were formed by the thermal decomposition of cobalt acetate $\left(\mathrm{Co}\left(\mathrm{CH}_{3} \mathrm{COO}\right)_{2} \cdot 4 \mathrm{H}_{2} \mathrm{O}\right)$, cobalt formate $\left(\mathrm{Co}(\mathrm{HCOO})_{2} \cdot 2 \mathrm{H}_{2} \mathrm{O}\right)$ or iron carbonyl $\left(\mathrm{Fe}(\mathrm{CO})_{5}\right)$ in a dispersion system of PTFE nanogranules in mineral oil ${ }^{311}$. An appropriate amount of metal-containing compounds was added to the high-temperature dispersed system. We discovered that granules of UPTFE make a fluidized bed on the surface of mineral oil ${ }^{31,32)}$. We used this effect for the nanometallization of nanogranules. Firstly, metallization of nanogranules occurs in the upper area of the fluidized bed. As the concentration of adsorbed metal-containing nanoparticles on the surface of PTFE increases, nanogranules move to the lower areas of oil and are removed from the reaction. The mineral oil was removed by washing with benzene in a Sohxlet apparatus. The resultant powder was dried in vacuum and stored in the air.
The optimum conditions were developed for the decomposition of metal-containing compounds in order to introduce highly reactive nanoparticles onto the polymer matrix with a concentration of 3-5 wt. \%

$\mathrm{N}$ anoparticles of cadmium sulfide stabilized on the surface of polytetrafluoroethylene nanogranules were obtained by analogy with an earlier-described technique for the nanometallization of ultradispersed polytetrafluoroethylene ${ }^{31,32)}$. Semiconductor nanoparticles of CdS were formed by a method of chemical modification, using barbotage of hydrogen sulfide through heated oil mixture of cadmium chloride nanoparticles on the surface of polytetrafluoroethylene nanogranules. Also, nanoparticles were doped by ions of manganese. It was carried out by the addition of manganese (II) acetate to the reaction mix.

The size of the nanoparticles was determined by transmission electron microscopy (TEM) studies using a JEOL JEM -100B microscope. The accelerating voltage was $80 \mathrm{kV}$. Samples were dispersed in the solvent using an ultrasonic oscillator. A drop of the solution was sputtered onto an amorphous carbon film deposited on a copper grid. After evaporation of the liquid, the samples were placed into the microscope.

$X$-Ray diffraction (XRD) measurements were made on powder samples with a DRON-3 diffractometer (CuK $\alpha$ radiation, $\lambda=1.54056 \AA$, scan speed of $2^{\circ} \%$ min). Peak positions were determined with an accuracy of $\pm 0.1^{\circ}$.

The temperature and field dependencies of magnetization were measured with the help of the vibrating sample magnetometer (model PARC-155, Princeton Applied Research) with a flow helium cryostat and a 
hromernade high-temperature insert. The magnetometer sensitivity is better than $5 \times 10^{-5}$ emu. The W magnetic measurements were carried out in the temperature range from 4.2 up to $380 \mathrm{~K}$ and in magnetic fields up to $7 \mathrm{kOe}$. M easurements of hysteresis loops were made by the first saturating of the sample in the field of $7 \mathrm{kOe}$.

Transmission and reflection spectra for the samples were fixed by means of a standard two-beam spectrophotometer CARY 2415 (VARIAN, USA). For elimination of spatial dependence of reflected and last light intensity measurement were studies using integrating sphere concerning the standard consisting from dispersed $\mathrm{BaSO}_{4}$. In view of the small sizes of samples, an entrance window of integrating sphere was blind.

\section{Results and discussion}

In order to confirm the presence of nanoparticles in the material and to determine their dimensions, we used transmission electron microscopy (TEM). Fig. 3 shows a TEM microphotograph of the sample containing 3.9 and $5.53 \mathrm{wt}$. \% of Co (from different precursors) on the surface of the PTFE nanogranule. According to the TEM data, the average size of the particles is 4.7 and $3.0 \mathrm{~nm}$. Fig. 4 shows a sample with $\mathrm{Fe}$-containing nanoparticles stabilized on the surface of PTFE. The average size is $6.0 \mathrm{~nm}$. The shape of Co- and Fe-containing nanoparticles is almost spherical. Elemental analysis showed that the cobalt content in the sample is $\approx 3.9$ and 5.53 wt. \% and the iron content is $\approx 4.1 \mathrm{wt}$. \%

The particles were analysed using XRD analysis and both diffraction patterns (Fig. $\mathbf{5}$ a, b) indicate the strong peaks of PTFE. Fig. $\mathbf{5}$ (a) shows a diffraction pattern for the sample containing $4.1 \mathrm{wt}$. \% of $\mathrm{Fe}$. There are characteristic peaks of $\alpha-\mathrm{Fe}, \gamma-\mathrm{Fe}_{2} \mathrm{O}_{3}$, $\mathrm{Fe}_{3} \mathrm{O}_{4}, \mathrm{FeF}_{3}$ and $\mathrm{Fe}_{3} \mathrm{C}$. For Co-containing nanoparticles on the surface of PTFE, the diffraction pattern in Fig. 5 (b) shows hexagonal $\mathrm{Co}, \mathrm{CoO}, \mathrm{CO}_{3} \mathrm{O}_{4}$ and $\mathrm{CoF}_{2}$ phases. $\mathrm{XRD}$ studies show that the obtained nanoparticles have a complex composition. That fact may be connected not only with conditions of synthesis but also with interaction between matrix and nanoparticles.

Fig. 6 (a) shows that at room temperature, the coercive force of the sample containing $3.9 \mathrm{wt}$ \% of $\mathrm{Co}$ on the PTFE is $300 \mathrm{Oe}$ and increases under cooling reaching the value of $600 \mathrm{Oe}$ at $4.2 \mathrm{~K}$, and the highest magnetization is about $0.4 \mathrm{emu} / \mathrm{g}$ (at $6 \mathrm{kOe}$ ). Fig. 6 (b) presents the temperature dependency of the magnetic moment (M) of the sample. The sample

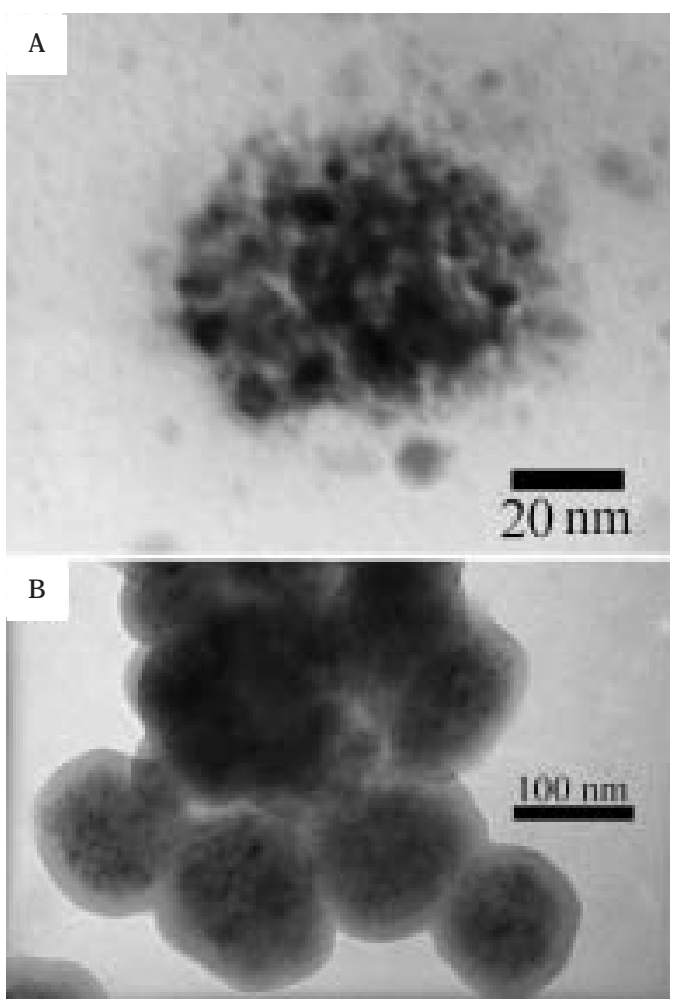

Fig. 3 TEM microphotograph of the sample containing 3.9 and 5.53 wt. \% of Co nanoparticles (A, B, - from acetate and formate, respectively) on the surface of PTFE nanogranules.

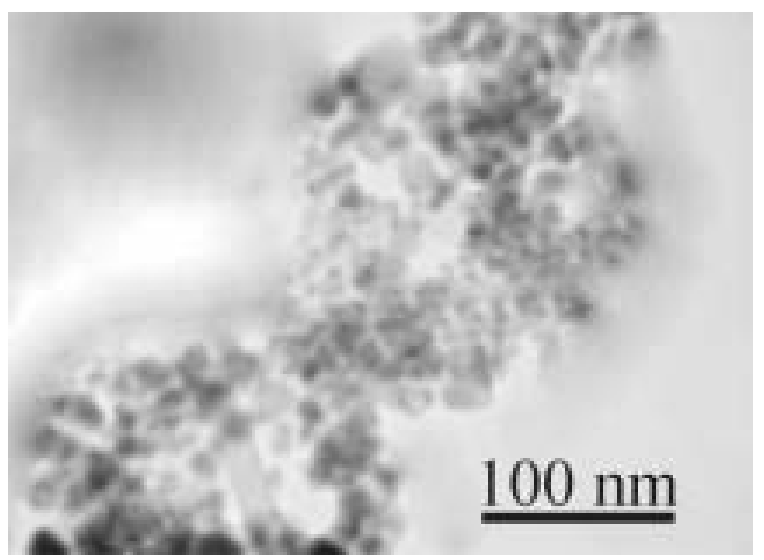

Fig. 4 TEM microphotograph of the Fe-containing nanoparticles stabilized on the surface of PTFE nanogranules.

was cooled from $300 \mathrm{~K}$ down to $4.2 \mathrm{~K}$ without applied magnetic field (ZFC procedure). The magnetic field was then applied and a heating procedure was performed. Above $\approx 25 \mathrm{~K}$, the temperature behavior of 

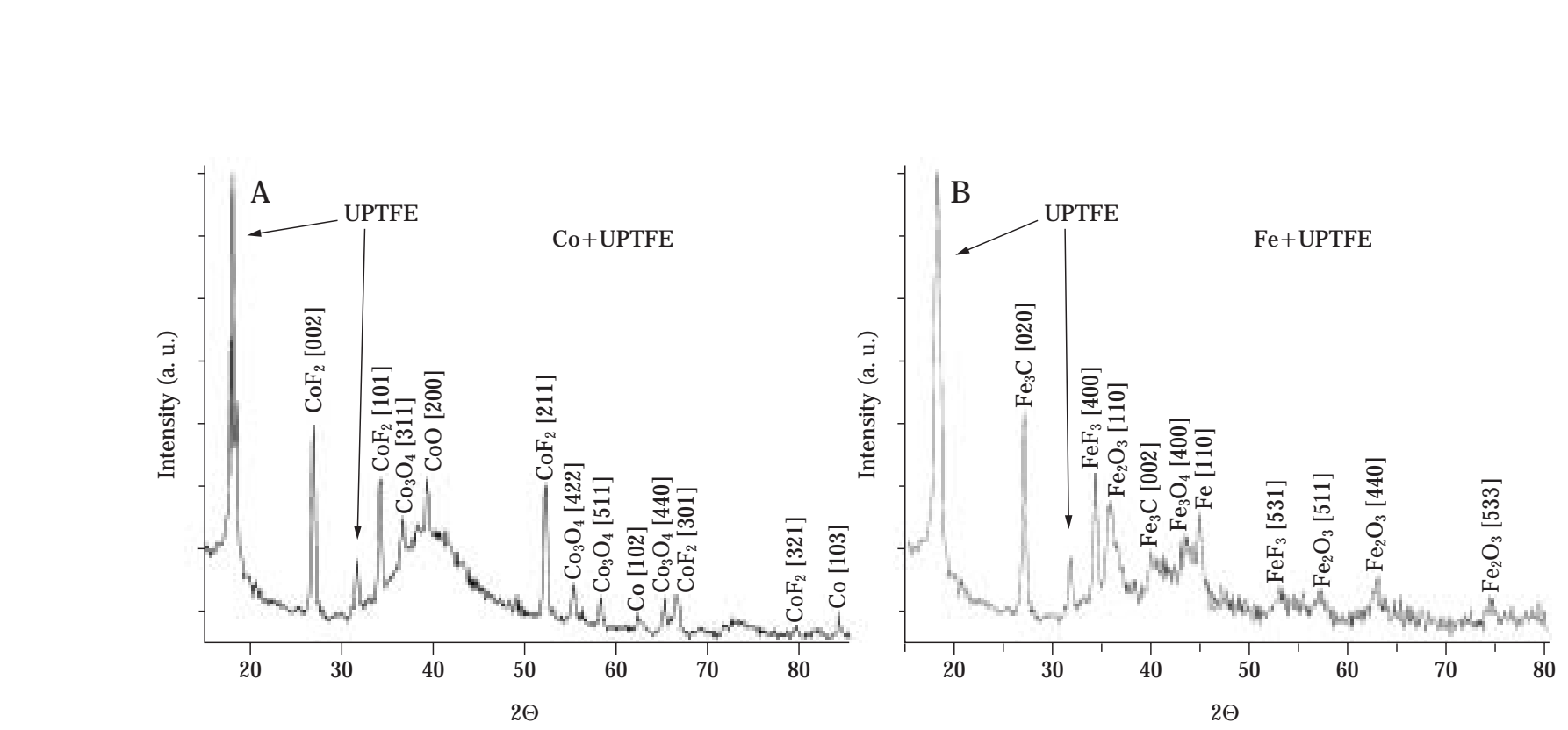

Fig. 5 Diffraction patterns for composite materials Co+UPTFE (a) and Fe+UPTFE (b).

the magnetic moment was typical of ZFC experiments for magnetic single-domain nanoparticles: the magnetic moment grew with temperature increase and reaches a maximum value at a temperature $T_{\max }$. If nanoparticles obey the log-normal size distribution, the temperature of the maximum magnetic moment is approximately equal to the average blocking temperature $\left\langle\mathrm{T}_{\mathrm{B}}>\right.$. In our case, $\mathrm{T}_{\max } \approx 270 \mathrm{~K}$. We can estimate the magnetic anisotropy as $\mathrm{K}_{\mathrm{V}} \approx 30 \mathrm{k}_{\mathrm{B}} \mathrm{T} / \mathrm{V} \approx 5 \cdot 10^{6} \mathrm{~J} / \mathrm{m}^{3}$ (for bulk $\mathrm{Co}_{0} \approx 10^{6} \mathrm{~J} / \mathrm{m}^{3}{ }^{33}$ ) .

Below $25 \mathrm{~K}$, the magnetic moment demonstrates unusual behavior (Fig. 6). We cannot exclude that the sharp increase of $M(T)$ with temperature decreasing might be due to the very small size of nanoparticles, which behave paramagnetically even at low temperatures. Another possible reason is the presence in our nanoparticles of the phase $\mathrm{CoF}_{2}$. It was found ${ }^{34)}$ that in bulk $\mathrm{CoF}_{2}$, the perpendicular magnetic susceptibility significantly grows below the Néel temperature $(\approx 38 \mathrm{~K})$. The magnetic properties of nanoparticles $\mathrm{CoF}_{2}$ are still unknown, but the general tendency of decreasing the critical magnetic temperatures in nanoparticles in comparison with bulk counterparts does not contradict this hypothesis. Fig. 6 (c) shows that at room temperature, the coercive force of the sample containing $5.3 \mathrm{wt}$. \% of Co (from cobalt formate) on the UPTFE is $800 \mathrm{Oe}$ and increases under cooling reaching the value of 1050 $\mathrm{Oe}$ at $77 \mathrm{~K}$, and the highest magnetization is about $153 \mathrm{emu} / \mathrm{g}$ (at $5 \mathrm{kOe}$ ). The received values of coercivity and magnetization are the highest for homometal- lic nanoparticles.

Fig. 7 (a) shows hysteresis loops at 5 and $300 \mathrm{~K}$ for the sample containing $4.1 \mathrm{wt}$. \% of Fe on UPTFE. According to magnetic measurements, Fe-containing nanoparticles demonstrate a typically ferromagnetic behavior. The coercive force at room temperature is $\approx 150 \mathrm{Oe}$ and $\approx 700 \mathrm{Oe}$ at $5 \mathrm{~K}$, and the highest magnetization is about $0.58 \mathrm{emu} / \mathrm{g}$ (at $7 \mathrm{kOe}$ ). The increase of coercive force under cooling was justified on the basis of the blocking state model. Fig. 7 (b) presents the ZFC procedure for Fe+UPTFE sample. The temperature behavior of the magnetic moment was typical for ZFC experiments on magnetic single-domain nanoparticles: the magnetic moment grew with temperature increase and after extrapolation, the average $\left\langle\mathrm{T}_{\mathrm{B}}>\right.$ is $\approx 765 \mathrm{~K}$. We can estimate the magnetic anisotropy as $K_{v} \approx 2.3 \cdot 10^{7} \mathrm{~J} / \mathrm{m}^{3}$ (for bulk $\mathrm{Fe} \mathrm{K}_{\mathrm{V}}$ $\left.\approx 4.5 \cdot 10^{6} \mathrm{~J} / \mathrm{m}^{3} 33\right)$.

Fig. 8 shows EPR spectra measured at different temperatures. The spectra have a complex structure, comprising at least from the three components: (1) a typical low-field ferromagnetic resonance (FM R) signal, (2) a relatively narrow line at $g=2.05$ with a peakto-peak width $\mathrm{DH}_{\mathrm{pp}} \approx 7 \cdot 10^{4} \mathrm{~A} / \mathrm{m}$, and (3) a very broad, poorly resolved line extending up to $6 \cdot 10^{5} \mathrm{~A} / \mathrm{m}$. This shows that the nanoparticles are quite uniform in size, the complex structure of the EPR spectrum suggests that the nanoparticles consist of several components. Based on the X-ray diffraction results on the percentages of iron, iron carbide and iron fluoride, we suppose that the relatively narrow EPR signal is due 

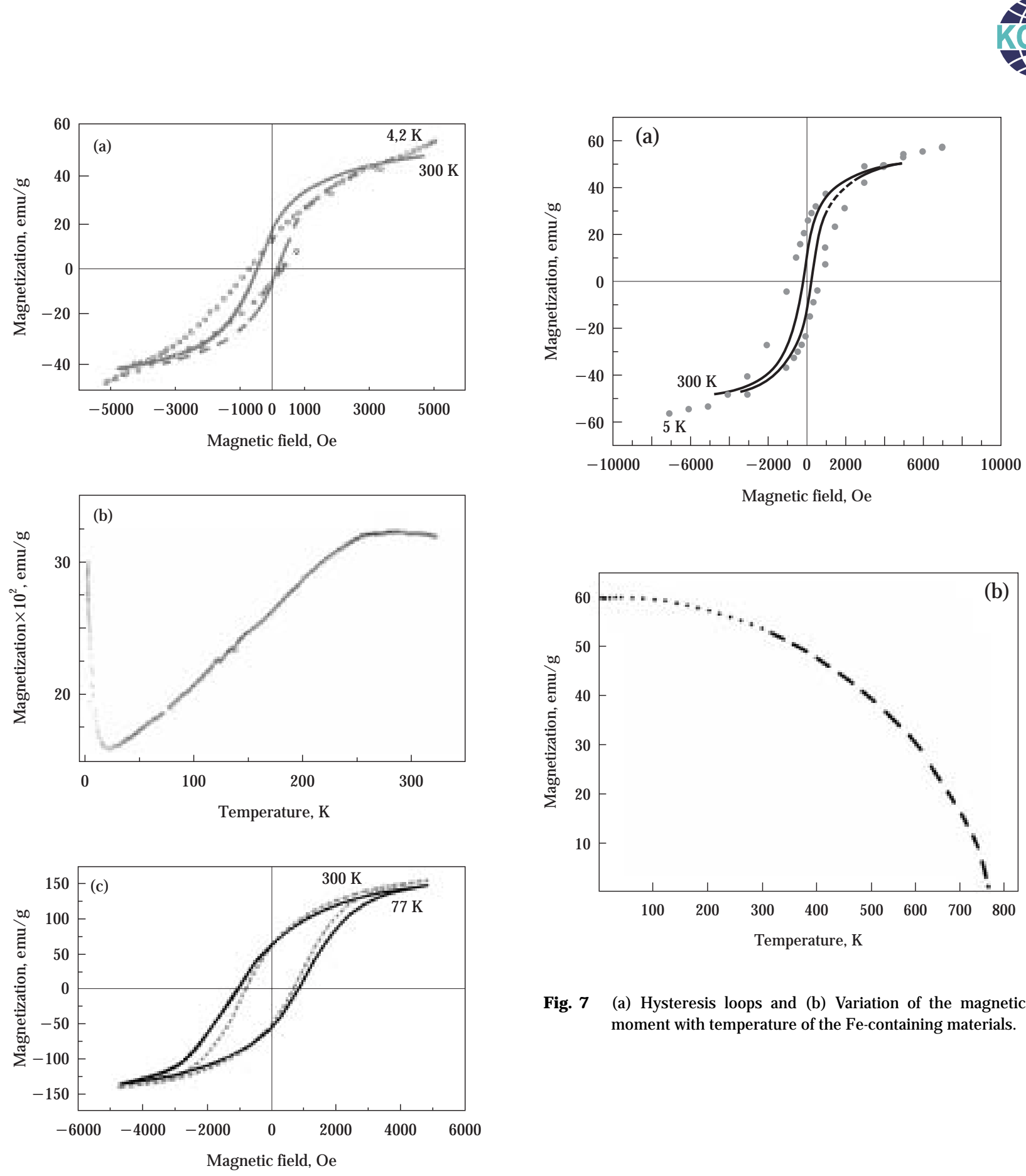

Fig. 7 (a) Hysteresis loops and (b) Variation of the magnetic moment with temperature of the Fe-containing materials.

Fig. 6 (a, c) Hysteresis loops and (b) Variation of the magnetic moment with temperature of the Co+UPTFE synthesized from acetate $(a, b)$ and formate $(c)$.

to iron oxide (which is present in a small amount and, hence, the corresponding regions of the particles are small in size), and that the low-field FM R signal arises from iron carbide (the largest volume fraction in each particle). The broad EPR line is attributable to iron fluoride (since this line was missing in the spectra of

Fe nanoparticles in polyethylene ${ }^{35)}$, where no fluorine could be present) or a-Fe, which is characterized by a very broad EPR signal ${ }^{36}$. With increasing temperature, the central EPR line becomes even narrower, $\mathrm{DH}_{\mathrm{pp}} \approx 5 \cdot 10^{4} \mathrm{~A} / \mathrm{m}$ at $355 \mathrm{~K}$, which is typical of the EPR spectra of nanoparticles. The low-field FMR signal becomes sharper with increasing temperature (Fig. 8).

Fig. 9 shows the EPR spectra measured in a magnetic field that was first gradually increased to $4 \cdot 10^{5}$ $\mathrm{A} / \mathrm{m}$ and then reduced to zero. Before measurements, the sample was shaken violently to eliminate its initial magnetic moment. It can be seen on Fig. 9 that, in the course of sample magnetization, the derivative microwave absorption signal does not revert 


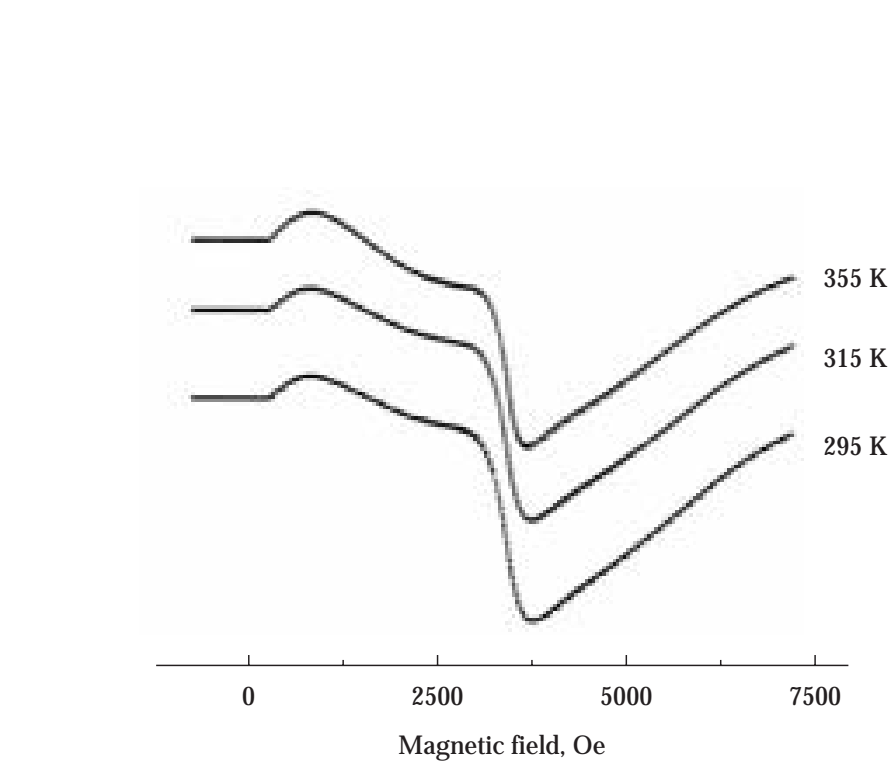

Fig. 8 EPR spectra measured at different temperatures for Fecontaining samples.

back to its initial level. This attests to a nonzero remanent magnetization $\mathrm{Mr}$. Using the method described previously ${ }^{37)}$, we obtained $M r \approx 4 \cdot 10^{5} \mathrm{~A} / \mathrm{m}$.

The quantum size effect in semiconductor nanoparticles has attracted much attention within the last few years. Besides the research of magnetic properties ${ }^{38)}$, proper attention and much time was found for studying the optical properties of semiconductor nanoparticles immobilized in various matrixes ${ }^{39,40)}$. Therefore, the nanomaterials consisting of nanogranules of PTFE with nanoparticles of cadmium sulfide and cadmium sulfide doped by manganese were also synthesized and investigated during our work. We have been exploring successfully our oil method for the immobilization of such nanoparticles on the surface of PTFE microgranules.

Fig. 10 shows a TEM microphotograph of the sample containing CdS nanoparticles on the surface of PTFE nanogranules. The average size of the particles is $5.0 \mathrm{~nm}$.

The particles were analysed using XRD analysis and both diffraction patterns (Fig. 11) indicate strong peaks of PTFE. Fig. 11 shows the diffraction pattern of the sample containing $14.0 \mathrm{wt}$. \% of CdS. There are characteristic peaks of hexagonal CdS. The changes in the absorption spectrum of $\mathrm{CdS}$ with changing particle size or with their introduction into the matrix are now well documented ${ }^{41)}$.

In Fig. 12, a comparison of the variation of the refractive index for nanomaterials on the base of CdSPTFE nanogranules with a concentration of 14 wt. \%

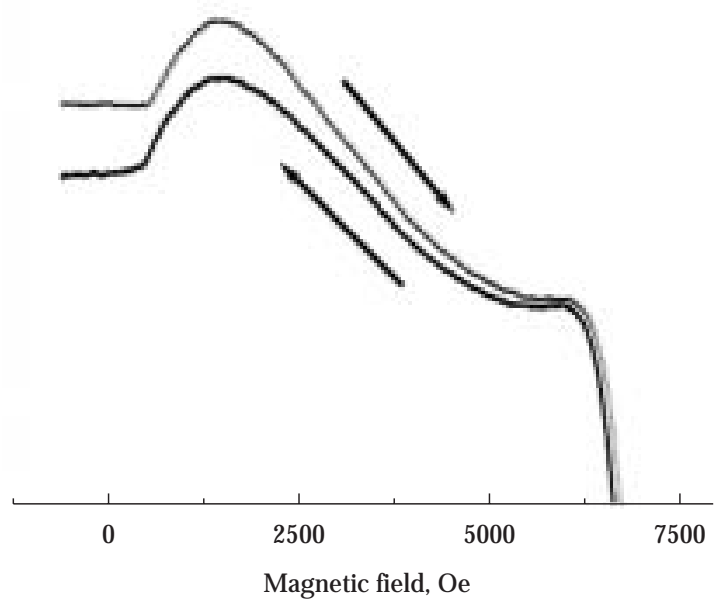

Fig. 9 M icrowave absorption hysteresis for Fe-containing samples at room temperature. The arrows indicate the fieldsweep direction.

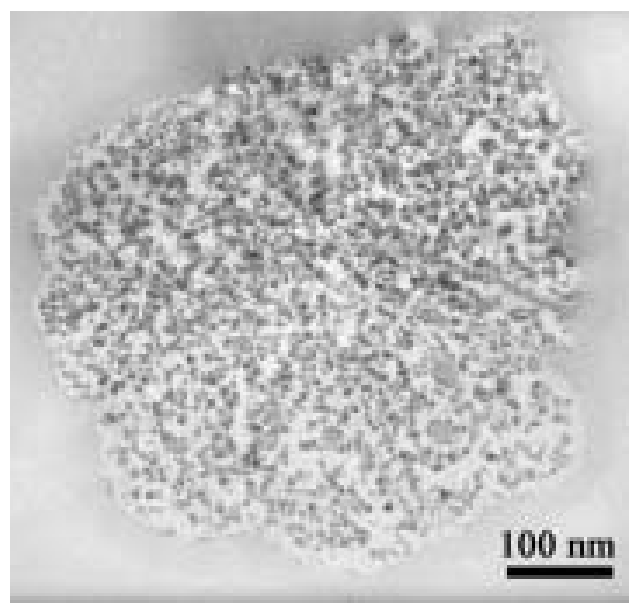

Fig. 10 TEM microphotograph of the sample containing CdS nanoparticles on the surface of PTFE nanogranules.

of CdS and for bulk crystals of cadmium sulfide are presented. These spectra unambiguously provide evidence that the particles of $\mathrm{CdS}$ have a crystalline structure and a good quality from the optical point of view at the same time. In contrast to bulk crystals of $\mathrm{CdS}^{42)}$ for which the refractive index has a normal character, nanomaterials on the base of CdS-PTFE nanogranules possess an abnormal character in the same spectral range. The detailed interpretation of this result is partially hindered by averaging out the inhomogeneous distributions of size, shape and sur- 


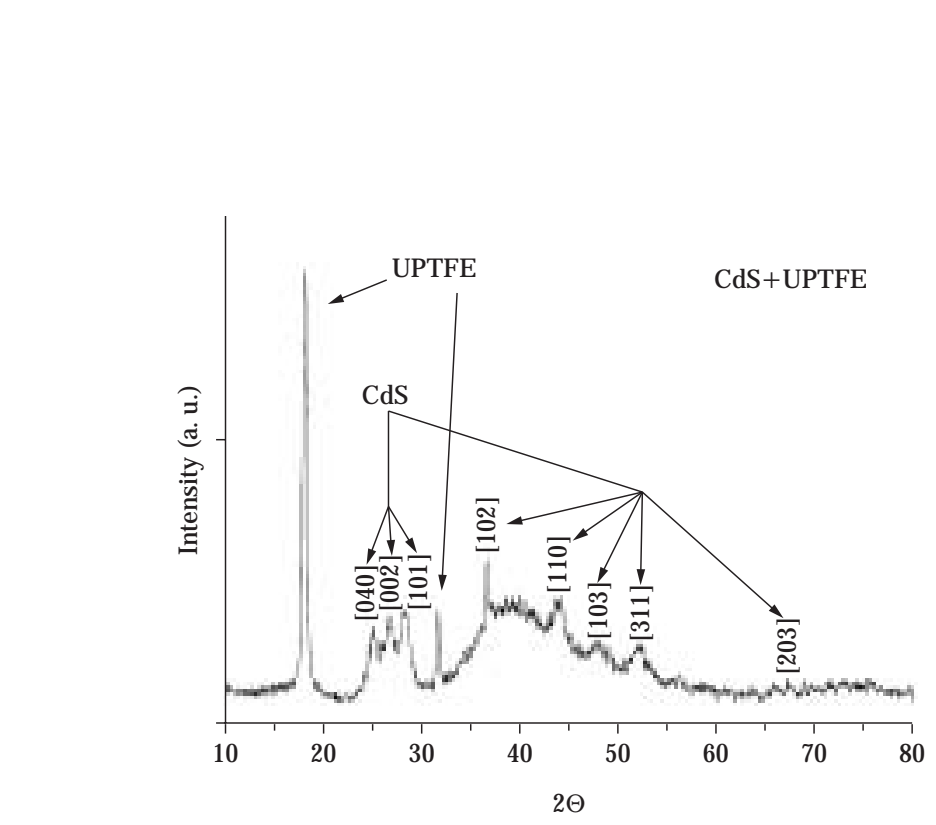

Fig. 11 Diffraction pattern of the sample containing CdS nanoparticles on the surface of the PTFE nanogranules.

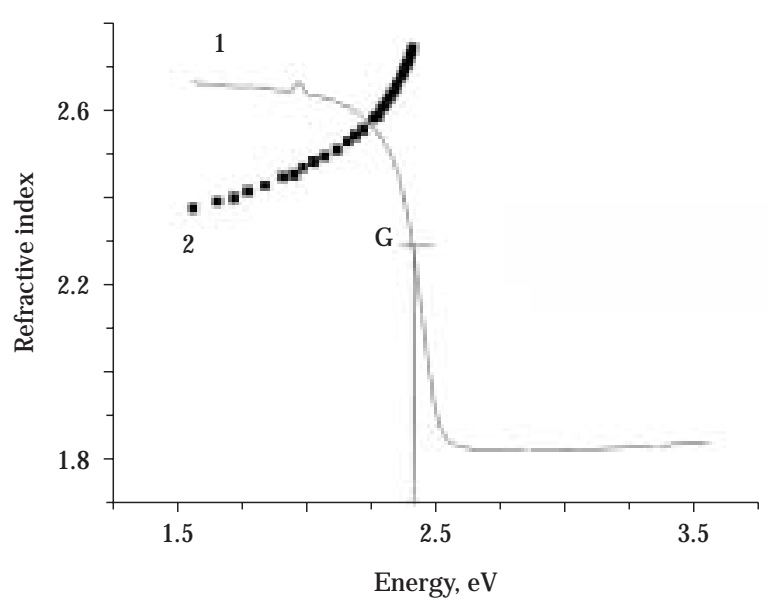

Fig. 12 Comparison of the variations of refractive index for nanomaterials CdS(14 wt. \%)-PTFE nanogranules (1) and for bulk crystal of cadmium sulfide (2).

face composition of nanoparticles.

Fig. 13 demonstrates the variations of the refractive index and absorption spectrum of the CdS-PTFE composite. The spectrum shows that a doping by manganese in a quantity up to $2 \mathrm{wt}$ \% from weight of $\mathrm{CdS}$ does not change the spectral characteristics as a whole, but leads to a small shift of the absorption edge to the shor ter optical wave length.

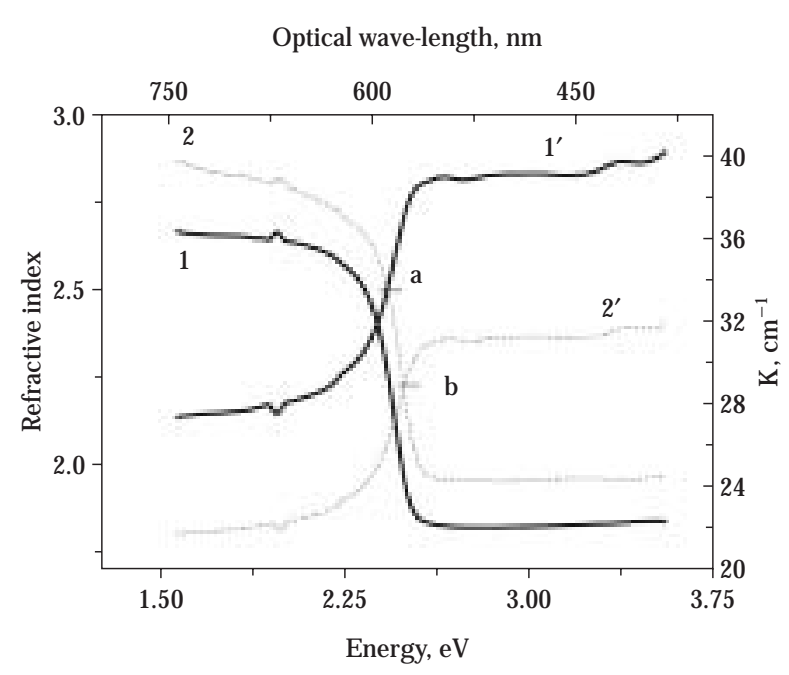

Fig. 13 Absorption spectra and variations in the refractive index of CdS-PTFE composite.

\section{Conclusions}

As a result, we made composite materials based on the magnetic and semiconducting nanoparticles stabilized on the surface of PTFE nanogranules.

The obtained magnetic nanoparticles are 4.7 and $3.0 \mathrm{~nm}$ in size for Co and $6.0 \mathrm{~nm}$ for Fe-containing nanoparticles. $M$ agnetic measurements show that the Fe-based composite material has a rather high blocking temperature $\approx 765 \mathrm{~K}$ and a coercive force of about $700 \mathrm{Oe}$ at $5 \mathrm{~K}$. Co-based materials have a rather high coercive force $\approx 600$ Oe at $4.2 \mathrm{~K}$ for the sample synthesized from cobalt acetate, and $1050 \mathrm{Oe}$ at $77 \mathrm{~K}$ for the sample obtained from cobalt formate. The received values of coercivity are the highest for homometallic magnetic nanoparticles. All these facts clearly demonstrate that the created nanomaterials with unique magnetic characteristics can be used in the same way as novel composite magnetic materials in which the unique properties of PTFE are supplemented by a high magnetic property.

The obtained semiconducting (CdS) nanoparticles are $5.0 \mathrm{~nm}$ in size. The spectral characteristics in visible and near IR regions of spectrum were specified. The influence of doping of nanoparticles by manganese ions on the absorption edge of nanomaterials was investigated. It was shown that such doping increases the width of the forbidden zone of a material on $0.1 \pm 0.01 \mathrm{eV}$. In comparison with bulk cadmium sulfide, the optical dispersion of nanomaterials has an abnormal character, and the ratio of frequency of the 
optican transition "zone-zone" to width of a line of absorpkion was 3.56, i.e. much less than for bulk materians. The measured index of refraction of nanomaterials containing 14 wt. \% of CdS on the surface of PTFE nanogranules was 2.3 , that practically agrees with an index of refraction of the bulk cadmium sulfide. Thus, by means of spectroscopy, the important properties of synthesized nanomaterials were specified. It is shown that semiconductor high-quality nanoparticles can be grown on the surface of a PTFE dielectric matrix. The obtained microgranule-nanopowders can be used as engineered nanopowders to meet the needs for new nanomaterials in biotechnology, sensors, optical transistors, optical switches, optical computing, photovoltaics, light emitting diodes (LEDs), shielding from UV-radiation, lasers or many other nano applications.

\section{Acknowledgements}

The experimental and theoretical analysis of the magnetic and optical properties of nanoparticles is the result of a close collaboration with Dr. Yu.A. Koksharov and Prof. N.M. Ushakov, respectively. The authors would like to acknowledge them.

This work was financed by the Russian Foundation for Basic Research (grant nos. 04-03-32090, 05-0332083), «Russian Science Support Foundation», the President of Russian Federation grant M K-2733. 2005. 3 , the Russian Academy of Sciences through the basic research program «Critical Issues in the Physics and Chemistry of Nanoscale Systems and N anomaterials» and «The directed synthesis of inorganic substances with the set properties and creation of functional materials on their basis».

\section{References}

1) Cao, Y.W.C.; Jin, R.C. and M irkin C.A.: Science, 297. 1536 (2002).

2) Alivisatos, A.P.: Nat. Biotechnol., 22. 47 (2004).

3) Tessler, N.; Medvedev, V.; Kazes, M.; Kan, S.H. and Banin, U.: Science, 295. 1506 (2002).

4) Klimov, V.; Mikhailovsky, A.; Xu, S.; Malko, A.; Hollingsworth, J.A.; Leatherdale, C.A.; Eisler, H.J. and Bawendi, M.G.: Science, 290. 314 (2000).

5) Kazes, M.; Lawis, D.Y.; Ebenstein, Y.; M okari, T. and Banin, U.: Adv. M ater., 14. 317 (2002).

6) Yin, Y.; Rioux, R.M.; Erdonmez, C.K.; Hughes, S.; Somorjai, G.A. and Alivisatos, A.P.: Science, 304. 711 (2004).

7) Martin, J.I.; Nogues, J.K.L.; Vicent, J.L. and Schuller, I.K.: J. M ag. M ag. M ater., 256. 449 (2003).

8) Kryszewski, M. and Jeska, J.K.: Synth. Met., 94. 99
(1998).

9) Park, I.W.; Yoon, M.; Kim, Y.M .; Kim, Y.; Kim, J.H.; Kim, S. and Volkov, V.: J. Mag. Mag. M ater., 272-276. 1413 (2004).

10) Respaud, M.; Broto, J.M.; Rakoto, H.; Fert, A.R.; Thomas, L.; Barbara, B.; Verelst, M.; Snoeck, E.; Lecante, P.; M osset, A.; Osuna, J.; Ould Ely, T.; Amiens, C. and Chaudret, B.: Phys. Rev. B, 57. 2925 (1998).

11) Fitz-Gerald, J.M.; Singh, R.K.; Gao, H. and Pennycook, S.J .: Kona, no. 17. 173 (1999).

12) Igarashi, T.; Kusunoki, T.; Ohno, K.; Isobe, T. and Senna, M .: M ater. Res. Bull., 36. 1317 (2001).

13) Ramesh, S.; Sominska, E. and Gedanken, A.: Utrason. Sonochem., 9. 61 (2002).

14) Sun, Y.-K.; Lee, Y.-S.; Yoshio, M. and Amine, K.: Electrochem. Solid-State Lett., 5. A99 (2002).

15) Fu, X. and Qutubuddin, S.: Colloids Surf. A., 178. 151 (2001).

16) Diaz, G.; Perez-Hermandez, R.; Gomez-Cortes, A.; Benaissa, M.; M ariscal, R. and Fierro, J.L.G.: J. Catal., 187. 1 ( 1999).

17) Deraz, N.M .: Colloids Surf. A, 190. 251 (2001).

18) Xuegang, L.; Gongying, L.; Zhanbo, S. and Wei, Z.: $M$ aterials Science and Engineering B, 117. 147 (2005).

19) O'Connor, C.J.; Sims, J A.; Kumbhar, A.; Kolesnichenko, V.L.; Zhou, W.L. and Wiemann, J.A.: J. Mag. Mag. M ater., 226-230. 1915 (2001).

20) J ordan, J.; Jacob, K.I.; Tannenbaum, R.; Sharaf, M.A. and Jasiuk, I.: Materials Science and Engineering $A$, 393. 1 (2005).

21) Tianbo, L.; Burger, C. and Chu, B.: Progress in Polymer Science, 28. 5 (2003).

22) Panshin, Yu.A.; M alkevich, S.G. and Dunaevskaja, Ts.S.: "Ftoroplasty", Khimija, Leningrad, Russia (1978).

23) Tsvetnikov, A.K.; Uminskii, A.A. and Tsarev V.A.: RU Patent 1763210.

24) Tsvetnikov, A.K.: RU Patent 2035308.

25) Tsvetnikov, A.K. and Uminskii, A.A.: RU Patent 1775419.

26) Tsvetnikov, A.K.; Bouznik, V.M. and M atveenko, L.A.: RU Patent 2100376.

27) Bouznik, V.M.; Fomin V.M.; Alhimov A.P. et al.: $M$ atallopolimernye nanokompozity (poluchenie, stroenie, primenenie). Izdatelstvo SO RAS, Novosibirsk, Russia (2005).

28) Kosobudskii, I.D. and Gubin, S.P.: Vysokomol. Soedin., 27. 689 (1985).

29) Gubin, S.P.; Yurkov, G.Yu. and Kosobudsky, I.D.: International J ournal of $\mathrm{M}$ aterials and Product Technology, 23.2 (2005).

30) Gubin, S.P.; Spichkin, Yu.I.; Yurkov, G.Yu. and Tishin, A.M.: Russian Journal of Inorganic Chemistry, 47 (suppl. 1). 32 (2002).

31) Gubin, S.P.; Korobov, M.S.; Yurkov, G.Yu.; Tsvetnikov, A.K. and Bouznik, V.M.: Doklady Chemistry, 388. 44 (2003).

32) Gubin, S.P.; Yurkov, G.Yu.; Korobov, M.S.; Koksharov, Yu.A.; Kozinkin, A.V.; Pirog, I.V.; Zubkov, S.V.; Kitaev, 
Varichev, D.A.; Bouznik, V.M. and Tsvetnikov, N.A.K.: Acta M aterialia, 53. 1407 (2005).

W33) Skomski, R.: J. Phys.: Condens. M atter, 15. R841 (2003).

34) Lines, M.E.: Phys. Rev. 137. A982 (1965).

35) Koksharov, Yu.A.; Gubin, S.P.; Kosobudsky, I.D.; Beltran, M .; Khodorkovsky, Y. and Tishin, A.M .: J . Appl. Phys., 88. 587 (2000).

36) Grinstaff, M.W.; Salamon, M .B. and Suslick, K.S.: Phys. Rev B , 48. 269 (1993).

37) Koksharov, Yu.A.; Blyumenfel'd, L.A.; Tikhonov, A.N. and Sherle, A.I.: Zh. Fiz. K him., 73. 1856 (1999).

38) Gubin, S.P.; Koksharov, Yu.A.; Khomutov, G.B. and Yurkov, G.Yu.: Russian Chemical Reviews, 6. 1 (2005).

39) Gubin, S.P.; Kataeva, N.A. and Khomutov, G.B.: Russian Chemical Bulletin, 4.1 (2005).

40) Klimov, A.: J. of Luminescence, 70.1 (1996).

41) Yoffe, A.D.: Adv. in Phys., 42.173 (1993).

42) Shakolskaia, M.P.: Acoustical crystals. Izdatelstvo Nauka, M oscow, Russia (1982).

\section{Author's short biography}

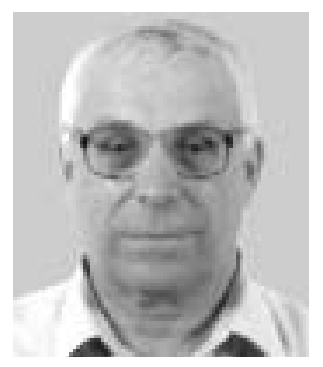

\section{S.P. Gubin}

Sergey Pavlovich Gubin was born in 1937 in M oscow. He is a professor and head of the Nanomaterials Chemistry lab of the N.S. Kurnakov Institute of General and Inorganic Chemistry of Russian Academy of Sciences, M oscow, Russia. He received his $\mathrm{BSc}$ and PhD degrees from the Chemical Department of M .V. Lomonosov M oscow State University and his DSc degree from the A.N. Nesmeianov Institute of Organo-Element Compounds of the Russian Academy of Sciences, M oscow, Russia. $\mathrm{H}$ is research has been reported in more than 400 primary publications and summarized in 10 review articles and four books and 6 inventions. Professor Gubin's current research focuses on clusters, nanoparticle chemistry and nanomaterials.

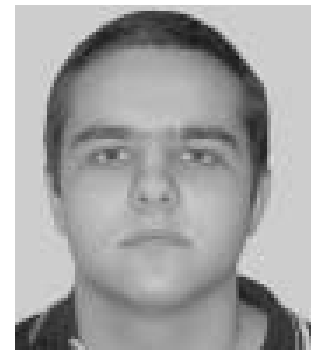

\section{I.P. Dotsenko}

Dotsenko Ivan Petrovich was born in 1984 in M oscow (Russia). In 2001, he completed his school studies with an in-depth study of foreign languages and simultaneously attended the evening school of the M oscow Chemical Lyceum. In 2001, he entered the Higher Chemical College of the Russian Academy of Sciences and in 2005 , he received his bachelor of science degree (chemistry). He is now studying for his master's degree. From February of 2002 till the present, he has been working as a senior laboratory assistant in the N anomaterials Chemistry Laboratory of the N.S. Kurnakov Institute of General and Inorganic Chemistry, Russian Academy of Sciences. Science interests: metal-containing nanoparticles, magnetic and electrophysical properties of nanomaterials. Ivan P. D otsenko is an author of 3 articles and a number of abstracts for international conferences.

\section{G.Yu. Yurkov}

Gleb Yurjevich Yurkov was born in 1976 in Grozny. In 1998, he graduated from the N.G. Chernishevsky Saratov State University. He received his PhD in inorganic chemistry in 2002 at the N.S. Kurnakov Institute of General and Inorganic Chemistry, Russian Academy of Sciences under the super vision of Professor S.P. Gubin. $\mathrm{He}$ is currently a senior researcher at the Nanomaterials Chemistry Laboratory at the N.S. Kurnakov Institute of General and Inorganic Chemistry, Russian Academy of Sciences. His main research interests include inorganic chemistry, the stabilization of nanoparticles, the synthesis and investigation of gomo- and getero-metallic nanoparticles and composite materials on the basis of nanoparticles and polymer matrixes. His research has been reported in more than 30 articles in international and Russian scientific journals and in 1 invention. 


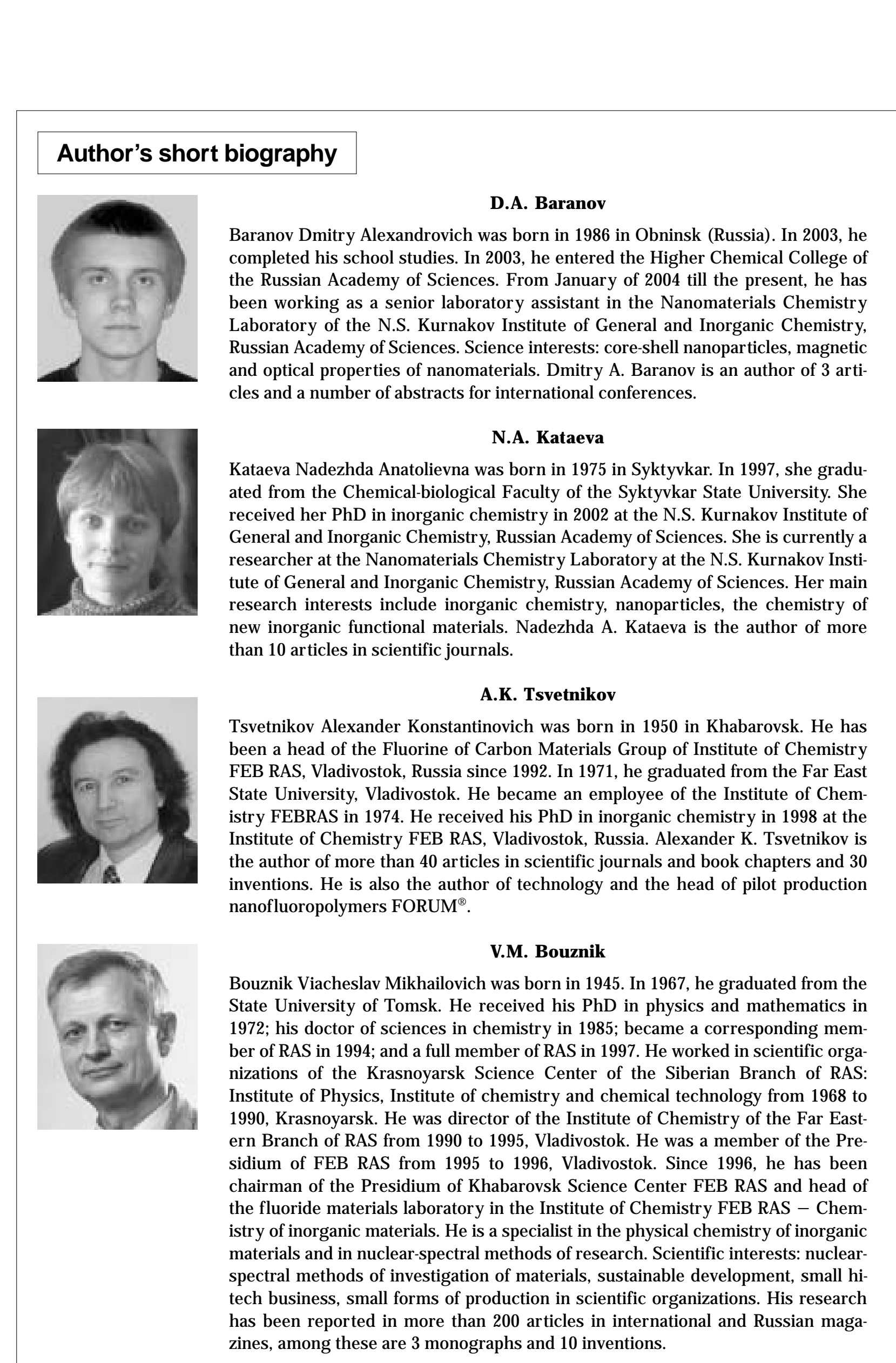

